\title{
"The perceived benefits and barriers to the application of mobile and social networking technologies in Higher Learning Institutions"
}

\begin{tabular}{|c|c|}
\hline AUTHORS & $\begin{array}{l}\text { Wellington Chakuzira } \\
\text { Armstrong Kadyamatimba }\end{array}$ \\
\hline ARTICLE INFO & $\begin{array}{l}\text { Wellington Chakuzira and Armstrong Kadyamatimba (2017). The perceived } \\
\text { benefits and barriers to the application of mobile and social networking } \\
\text { technologies in Higher Learning Institutions. Problems and Perspectives in } \\
\text { Management, 15(3), 343-351. doi:10.21511/ppm.15(3-2).2017.04 }\end{array}$ \\
\hline DOI & http://dx.doi.org/10.21511/ppm.15(3-2).2017.04 \\
\hline RELEASED ON & Monday, 04 December 2017 \\
\hline RECEIVED ON & Tuesday, 27 June 2017 \\
\hline \multirow[t]{2}{*}{ ACCEPTED ON } & Monday, 02 October 2017 \\
\hline & $( \infty ) \longdiv { \text { EY-NC } }$ \\
\hline LICENSE & $\begin{array}{l}\text { This work is licensed under a Creative Commons Attribution-NonCommercial } 4.0 \\
\text { International License }\end{array}$ \\
\hline JOURNAL & "Problems and Perspectives in Management" \\
\hline ISSN PRINT & $1727-7051$ \\
\hline ISSN ONLINE & $1810-5467$ \\
\hline PUBLISHER & LLC "Consulting Publishing Company "Business Perspectives" \\
\hline FOUNDER & LLC "Consulting Publishing Company "Business Perspectives" \\
\hline
\end{tabular}

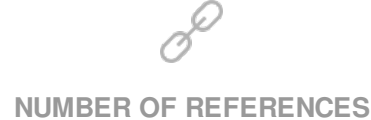

16

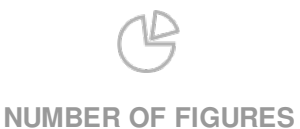

3

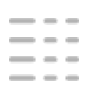

NUMBER OF TABLES

2

(C) The author(s) 2023. This publication is an open access article. 




BUSINESS PERSPECTIVES

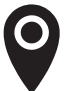

LLC "CPC "Business Perspectives" Hryhorii Skovoroda lane, 10, Sumy, 40022, Ukraine

www.businessperspectives.org

Received on: $27^{\text {th }}$ of June, 2017 Accepted on: $2^{\text {nd }}$ of October, 2017

(C) Wellington Chakuzira, Armstrong Kadyamatimba, 2017

Wellington Chakuzira, MCom in Business Management and PhD candidate, School of Management Sciences, University of Venda, South Africa.

Armstrong Kadyamatimba, $\mathrm{PhD}$, Professor in Business Information Systems, School of Management Sciences, University of Venda, South Africa.

\section{(ㄷ)(1) $(8)$}

This is an Open Access article, distributed under the terms of the Creative Commons Attribution-NonCommercial 4.0 International license, which permits re-use, distribution, and reproduction, provided the materials aren't used for commercial purposes and the original work is properly cited.

\begin{abstract}
This research investigated on the perceived benefits and barriers to the application of mobile and social networking technologies in South African Higher Learning Institutions (HLIs). A quantitative orientation was used in carrying out the study through self-administered questionnaires and a descriptive quantitative method of analysis was applied. The research population consisted of some students and lecturers from University of Venda (Univen) and University of Limpopo (UL). The research results showed that in deed HLIs in South Africa enjoy some benefits using mobile and social networking technologies which makes students and lecturers participate in virtual learning. The results also confirmed that HLIs in South Africa are faced with various barriers affecting mobile and social networking technology adaptations. Five noteworthy barriers identified were connectivity, security problems, small screens, lack of equipment and technology and lack of training among users. Benefits which were identified included, improved participation, improved communication between students and lecturers and enhancement of teaching and learning processes in HLIs. The research recommended HLIs to be aware of the major Learning Management Systems (LMS) which they should use together with social networking platforms to successfully gain full benefits of using mobile and social networking technologies in the education sector.
\end{abstract} institutions, learning management systems, mobile computing, smartphones

\section{JEL Classification I2, I23, L15, L86, M15}

\section{INTRODUCTION}

The mobile phone industry is distinctive in its level of technological change. New handsets are emerging in the market daily and these mobile handsets are offering a wide range of services (Banks \& Burge, 2004). Banks and Burge also stated that mobile phone is now turning into an important information communication device aided by several applications such as the Short Message Services (SMS), as well as the Internet. In most developing countries including South Africa, mobile devices are certainly changing the society. Together with other types of Information Communication Technologies (ICT), the mobile phone is conveying teaching and learning opportunities to both students and lecturers (Banks \& Burge, 2004). As with many other technologies, the Internet has a great impact on Higher Learning Institutions (HLI). The Internet can provide a direct connection between universities and students by creating a virtual learning environment (Leung \& Wei, 2000). Leung and Wei identified motivation factors for the use of the Internet as 24/7 accessibility (ubiquity), information rich and update, seeing/comparing options, global reach, control over decision, cost effective and instant gratification. 


\section{LITERATURE REVIEW}

This study was guided by the theoretical work which was discussed by Selwyn (2012) which identified the key features of social networking technologies and their significance to contemporary higher education. Selwyn claimed that growing numbers of educationalists are now considering the possible significance and likely implications of social networking technologies for teaching and learning practice.

\subsection{Revisiting the term mobile social networking}

The term mobile social networking is an extension of social networking where individuals with similar interests converse and connect with one another through their mobile phones and/or $\mathrm{P} / \mathrm{C}$ tablets and the use of existing social networks to create native communities and promote discovery, and webbased social networks to take advantage of mobile features and accessibility (Lu, Yu, Guo, \& Zhou, 2014). However, m-learning or mobile learning is simply defined as learning across multiple contexts, through social and content interactions, using personal electronic devices (Lu et al., 2014). Therefore, it can be seen as a form of virtual distance education, which facilitates $\mathrm{m}$-learners to use mobile device for educational purposes at any time and any place. It is also important to note that modern day universities are experiencing cloud based technologies where a number of internet services for different HLIs are hosted and serviced by a particular outsourced bigger server such technologies are being appreciated with the notions of Information Technology (IT) support being decentralised (Chen \& Almunawar, 2016). Adoption of cloud-based applications and services are altering the ways we configure and use software, configure file storage and conceptualize functions (Mircea \& Andreescu, 2011).

\subsection{Role of mobile and social networking technologies}

Mobile computing seeks to integrate mobile devices (smartphones, personal digital assistant (PDAs), iPods and $\mathrm{P} / \mathrm{C}$ tablets) into our daily lives. Currently, mobile learning integrates advances from elec- tronic learning and mobile computing (Magrath \& McCormick, 2013). This creates and completes the most important role of mobile and social networking technologies in virtual learning which is to build a teaching and learning platform where lecturers and students can enjoy teaching and learning at any place and anytime. The ultimate goal is to provide learners with better learning experience in their daily learning environments (Larivière, Joosten, Malthouse, Van Birgelen, Aksoy, Kunz, \& Huang, 2013). The required course outlines or study guides can be uploaded on a Learning Management System or a social network platform by lecturers. Students will gain access to the learning content and interact with their lecturers whenever they need it in different areas of life, regardless of space and time.

Madiba and Cross (2005) note that previously social networking technologies at universities were used for enriching their socialization process among students at universities. However, with more technological advancement, social networking blended with m-learning are providing universities with new experiences in the learning and teaching environment both formally and informally (Sharples, 2006). Social networking also help universities to build and sustain bonds between people, making people to go on it for educational purposes. Moreover, social networking technologies are now increasingly used by students for contacting other students to organise group meetings for academic project work, revision and coursework queries.

This study was guided by the theoretical work which was discussed by Selwyn (2010) which identified the key features of social networking technologies and their significance to contemporary higher education. Selwyn (2010) claimed that growing numbers of educationalists are now considering the possible significance and likely implications of social networking technologies for teaching and learning practice.

\subsection{Great acceptance and fast growth of social networking sites}

The literature available also identifies that there is great acceptance and fast growth of Social Networking Sites (SNSs) representing a unique opportunity to develop the connections of stu- 
Table 1. Type of activity supported by social networking platforms

Source: Alassiri, Muda, Ghazali, and Ahamefula (2014).

\begin{tabular}{|c|c|}
\hline Type of activity & Typical instances social network is used \\
\hline Group discussion & $\begin{array}{l}\text { Twitter can be used during elections of students' representatives in HLIs using different } \\
\text { languages. Facebook can also be used to interact and discuss with a group of learners } \\
\text { and or academics during a semester or a term }\end{array}$ \\
\hline Organize events & $\begin{array}{l}\text { Facebook and Twitter online social networks are to send video clips, message and } \\
\text { posters for important class events such as presentation dates and important test dates }\end{array}$ \\
\hline Access information & $\begin{array}{l}\text { Professors, presenters and leaders of an educational conference can use Twitter } \\
\text { feeds to access information on what was happening during and after the conference. } \\
\text { The students can access local journals, as well as international journals plus } \\
\text { community radios }\end{array}$ \\
\hline Publish opinions and receive feedbacks & $\begin{array}{l}\text { University of Venda in South Africa and a number of HLIs in the country and around } \\
\text { the globe have Facebook sites which can be used to discuss ongoing process of these } \\
\text { HLIs development strategies pertaining to the growth and learning qualities of a } \\
\text { particular university }\end{array}$ \\
\hline
\end{tabular}

dents to a deeper understanding of different culture (Lai, Khaddage, \& Knezek, 2013). Given the global growth and the highly social nature of SNSs, the social connections of students for example in South Africa might be influenced by SNSs. Students at different HLIs encounter cultural differences, academic challenges, and psychological and social adjustments (Larivière et al., 2013). Formation of SNSs groups facilitates exchange of ideas and concerns. SNSs may be advantageous if tools could be delivered to encourage diverse interaction by SNSs, such as Facebook. Students may as well design mediums for them and faculty to communicate informally about both educational and personal issues. Such implementations simplify connection between students and lecturers as well as providing a mechanism for building peer care among students (Park \& Lim, 2014). All these changes facilitated diverse activities provided by social networking platforms that supports social and academic development of students at different HLIs. Table 1 provides a list of activities supported by social networking site application and instances they are used.

Literature also supports the fact that students and lecturers are increasingly partaking into virtual methods of connection, hence, they digitally communicate with each other in ways that would have been impossible only a few years ago (Osang, Ngole, \& Tsuma, 2013). Such forms of communications are facilitated by the undisputable penetration of mobile devices, PDAs, MP3 players, PC tablets, and laptops (Osang et al., 2013). With such infiltrations in place, HLIs are now looking for ways to integrate mobile computing into m-learning to make teaching and learning more manageable and convenient.

\subsection{Factors for adaptation}

A number of factors such as manageability, affordability and ease of use facilitated the adaptations of these devices. The devices allow lecturers to post or upload assignments while students may have access to learning material at any time and any place, for example, students can use PDAs on field trips to collect, store, and analyze data on site. This is supported by Wankhade and Deshpande (2015) who predicted a growth in the market of portable computing devices, as well as e-books. Such developments indicate the growing need of mobile learning adaptations within HLIs. However, these technological advancements like e-books might come along with an ebook software and new usability standards. Such software and standards usually eliminates the widespread adoption of these applications in the near future.

\subsection{Goal of the study}

Both University of Limpopo and University of Venda are using blackboard as Learning Management Systems (LMS). However, the challenges remain specifically linked to the notions of privacy and sovereignty, although promise of significant cost savings through easy access and easy availability of information among students and lecturers are important drivers to such solutions. There is a greater need to support growing number of students in universities with HLIs across the world looking for ways to control costs while providing quality services to the modern dynamic market. 
The study investigated the opportunities which mobile technological advancement is bringing to both universities (University of Venda and University of Limpopo) and students. It also looked at the barriers which are slowing down the rate of m-learning and social networking technologies adaptation by these universities. This was to help students, lecturers and non-academic staff members in conceptualizing mobile learning and social networking measures that enhance a student-oriented m-learning strategy in South African universities. The study was guided by the following research questions:

\subsubsection{Research questions}

- What factors are promoting the growth of $\mathrm{m}$ learning and usage of social networking technologies in South African universities?

- What challenges have been faced by University of Venda and University of Limpopo in using mobile and social networking technologies to improve teaching and learning practices?

- What are the mobile and social networking technologies currently used by students at University of Venda and University of Limpopo?

\section{RESEARCH METHODS}

\subsection{Participants and setting}

The study adopted a quantitative approach to test the different opportunities, as well as barriers which affect mobile and social networking technology adaptations in South African universities. It is based on a non-probabilistic and self-selection sampling method, a convenience sample. More specifically, the data were collected by means of self-administrated questionnaire containing a list of questions from students and lecturers. 160 students and 50 lecturers who surveyed were from the two universities $(n=84$ students University of Venda, $n=76$ students University of Limpopo and $n=25$ lecturers from University of Venda and Limpopo, respectively).
Before conducting this research work, ethical clearance was sort and granted by the University of Venda Research Ethics Committee. All participants individually consented.

\subsection{Data analysis}

The descriptive quantitative method of analysis was applied in the study. Content coding was firstly done to change the open responses of the participants to descriptive data. The purpose of the coding was to classify responses into meaningful categories and then assign frequencies to the responses. Eventually, all the enumerated data was analysed using IBM Statistical Package for Social Sciences (SPSS) V 22.0.0.0.

\section{RESULTS AND DISCUSSIONS}

\subsection{Mobile devices used by students and lecturers}

As shown in Figure 1, three important devices used by majority of students and lecturers in the two universities were identified as tablets, i-Pads and smartphones, while minority use other devices such as laptops and desktops for interaction with peers. The respondents expressed that tablets are very flexible mobile devices and they allow greater communication, which is two-way and assists greatly in developing a stronger bond between the students and lecturers as supported by Osang et al. (2013). Of the $30 \%$ who indicated that they use smartphones, it must be said that the smartphones are the best for students and lecturers, as it allows to message and call services which were already being offered by the telephone and texting services on cell phones (Park \& Lim, 2014). In addition, smartphones calls are free when using WhatsApp calls, which is beneficial to students in their daily interaction. In addition, smartphones calls are free when using WhatsApp calls, which is beneficial to students in their daily interaction. They also added that they use this service for conferencing calls and group talks among students or with students and their lecturers. 


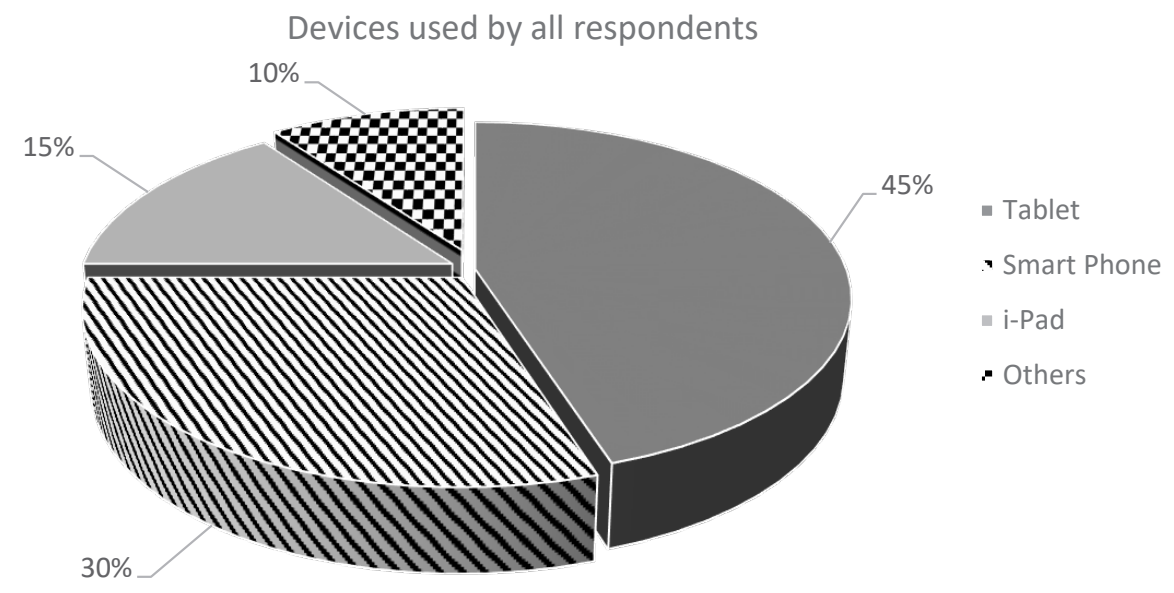

Figure 1. Devices used in Higher Learning Institutions

\subsection{Social networking sites used by students and lecturers}

Five major social networking platforms used by students and lecturers in the two universities were found out to be Facebook, WhatsApp, YouTube, Twitter and LinkedIn as depicted at Figure 2. Results shows that $41 \%$ of the participants indicated that they use Facebook application on their mobile gadgets and 33\% indicated that they use WhatsApp. 14\% of the respondents indicated that they use YouTube, whilst 9\% use Twitter on their mobile gadgets and the remaining $3 \%$ use LinkedIn.

\section{a) Facebook}

Of the $41 \%$ who use Facebook, it might be of the reason that Facebook has proved to be the leading social networking site and it has many added values that include photos uploading, updating school events, special calendar dates and events. This supports the statement expressed by Bullas (2012), which states that Facebook allows greater communication, which is two-way and assists greatly in developing a stronger bond between the lecturers and students in University of Venda and University of Limpopo.

\section{b) WhatsApp}

For the 33\% who indicated that they use WhatsApp, it might be because that WhatsApp is the best for their units, as it allows messaging and calling services which were already being offered by the telephone and texting services on cellphones. WhatsApp also allows free calls which is beneficial to students and lecturers in both University of Venda and University of Limpopo. WhatsApp calls is used more often to engage other students or lecturers so that information pertaining to the time and place of discussion will be clear to everyone. Such a service will also be used for conferencing calls and group talks with various experienced professors, as well as different academia around the globe.

\section{c) YouTube, Twitter and LinkedIn}

The participants who indicated that they use YouTube, because YouTube is the current application and it allows students and lecturers to up-

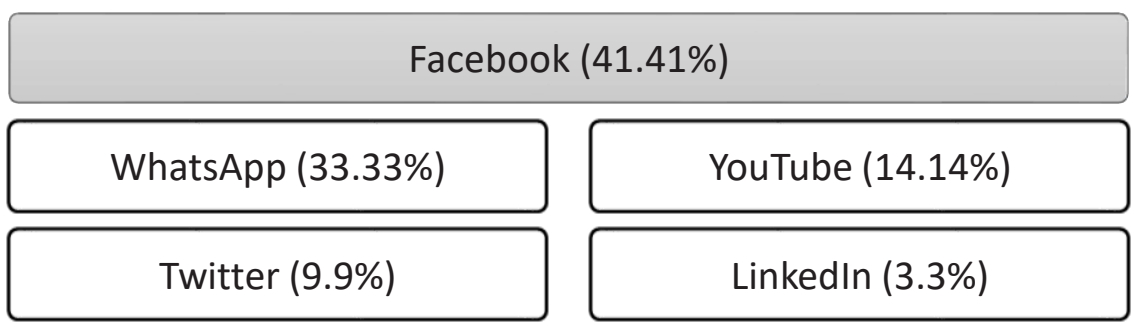

Figure 2. Social networking sites used by respondents 
load videos in their teaching, as well as learning experiences which can be viewed by everyone online. The $9 \%$ who use Twitter may be of the view that creation of a following with whom you constantly interact with and exchange information with. Students and lecturers update their current and potential papers or topics to those who follow them. Of the $3 \%$ of indicated that they have LinkedIn in their facilities were of the opinion that LinkedIn assists them in information disseminations amongst other professional colleagues.

\subsection{Benefits derived from using mobile and social networking technologies}

Three important benefits derived from using mobile and social networking technologies by students and lecturers in University of Venda and University of Limpopo were identified and analyzed namely improved teaching and learning, improved communication, and enhanced participation (see Figure 3).

According to Figure 3, most of the respondents indicated that they derived some sort of benefit from using mobile and social networking technologies in their HLIs. The respondents were asked to show the extent they agree to the fact that they are enjoying some benefits when using mobile and social networking technologies for teaching and learning. These benefits included improved teaching and learning (92\% agree, $4 \%$ neutral and $4 \%$ disagree), improved communication (88\% agree, $3 \%$ neutral and 9\% disagree,), and participation (78\% agree, $17 \%$ neutral and 5\% disagree).

\section{a) Improved teaching and learning}

It is important to say that majority of the students and lecturers about $92 \%$ in the survey supported the fact that mobile and social networking technologies improve teaching and learning in HLIs. Such technologies enhance teaching and learning because of the availability of more information on the Internet which students and lecturers can access freely and easily. The problem will be if these lecturers and students are able to select information which is relevant to their studies.

\section{b) Improved communication and enhancement of participation}

Mobile and social networking technologies are also improving communication in University of Venda and University of Limpopo as seen by $88 \%$ of the respondents who agree to this fact. These technologies provide a two-way communication link between students and lecturers in the form of chat rooms and discussion groups. Students and lecturers are now encouraged to strongly participate in academic advancement programs which are found online. This is supported by $78 \%$ of the respondents who agreed to the fact that there is increased participation in the usage of these platforms for educational purposes in HLIs.

HLIs can also use mobile and social network platforms for advertising, although the core purpose of their creation is networking. The SNSs can also be used to market both the courses offered at an HLI and wide range of benefits which people accrue by enrolling at a specific HLI. These packages and any upcoming specials are uploaded and up-

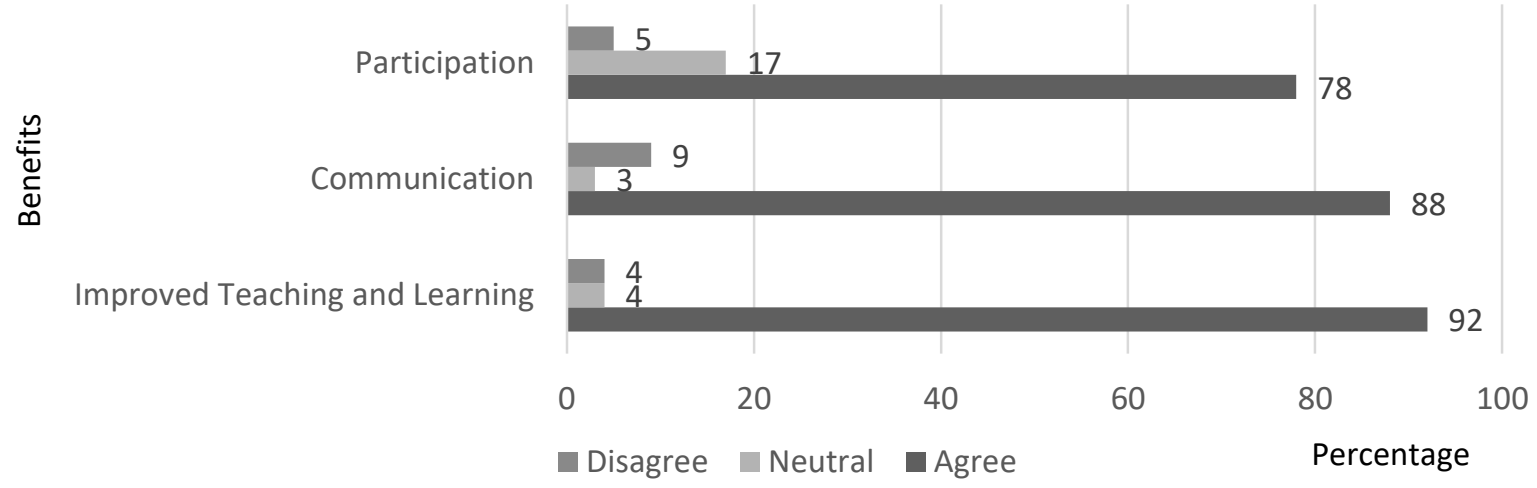

Figure 3. Benefits enjoyed by lecturers and students 
dated on the various sites, especially Facebook and Twitter. Other activities such as online registration and market intelligence can also be enjoyed by HLIs who successfully implement mobile and social networking technologies. The problems which are associated with these benefits are discussed in the next series of results.

\subsection{Challenges faced by students and lecturers when using social networking services}

Seven eroding barriers derived from using mobile and social networking technologies by students and lecturers in the two universities were identified and analyzed (see Table 2).

The results in Table 2 indicated that most of the respondents encountered some challenges using mobile and social networking technologies in their universities, especially network- and connectionrelated problems. The respondents were asked to show the extent to which they experienced challenges when using these technologies. These challenges include, distraction (52\% agree, $11 \%$ neutral and $37 \%$ disagree), small screens of the gadgets (54\% agree, 24\% neutral and 22\% disagree), connectivity and battery life (57\% agree, $16 \%$ neutral and $27 \%$ disagree), lack of technology ( $86 \%$ agree, $5 \%$ neutral and $9 \%$ disagree), viruses (64\% agree, $22 \%$ neutral and $14 \%$ disagree), training (69\% agree, $10 \%$ neutral and $20 \%$ disagree) and poor connection (67\% agree, $11 \%$ neutral and $21 \%$ disagree).

As for the respondents that cited connectivity, as well as poor connection, such respondents usually experience delays in information retrieval, as well as poor download times when trying to access journals or books on the Internet. Furthermore, it was observed that long download times and poor connectivity frustrates students and lecturers to the extent that they end up preferring the old traditional systems of teaching and learning. Of the respondents that cited small screens of gadgets as a problem, it might be because a lot of lecturers and students lack confidence on their small smart phones with small screens. Students and lecturers failed to read and analyze diagrams properly which they would have downloaded due to small screens. However, it must be said that the introduction of $\mathrm{P} / \mathrm{C}$ tablets is solving this problem, since such devices are designed with bigger screens.

Whilst the rest of students and lecturers cited the abovementioned issues, those who cited viruses are mainly concerned with the insecurities of online Internet systems on social networking sites. They probably have a lot of security concerns on the social media network system. Although the platforms make information readily available to both lecturers and students and also increase information density around HLIs campuses, they usually fail to provide any security systems which help students and lecturers. Usually students' data can be attacked by viruses or other malicious ware and some documents on the Internet will fail to open due to such forms of attack. However, data can be encrypted or students and lecturers can use antiviruses to minimize the impact of all these problems.

Other respondents' results indicated training needs as one of the major challenge of using and adoption mobile and social networking technology in HLIs in South Africa. This might be attributed to the belief of the South African HLIs users who lack confidence in the usage of these technological advancements. The main reason might be because many have a tendency of a wait and see attitude which make them not se-

Table 2. Challenges faced by lecturers and students

\begin{tabular}{|c|c|c|c|}
\hline Challenges & Agree $\%$ & Neutral \% & Disagree $\%$ \\
\hline Distraction & 52 & 11 & 37 \\
\hline Small screens & 54 & 24 & 22 \\
\hline Connectivity and battery life & 57 & 16 & 27 \\
\hline Lack of technology & 86 & 5 & 9 \\
\hline Viruses & 64 & 22 & 14 \\
\hline Training & 70 & 10 & 20 \\
\hline Poor connection & 67 & 11 & 22 \\
\hline
\end{tabular}


riously commit to the upcoming and ever-changing technology. Most of the HLIs senior executive personnel is reactional and not pro-active to capitalize on the new technologies.

This group was of the opinion that management itself needs to be trained and educated so that they take it seriously to the extent of including such technological goals in their long-term plans if HLIs are to succeed in the adoption of mobile and social networking technologies. On the one hand, those who mentioned distraction as problem are concerned with the abuse of social networks by students and lecturers in the use and adoption of mobile and social networking technologies in HLIs. Students and lecturers tend to abuse and concentrate much of their time on personal servicing rather information sharing and retrieval for teaching and learning when logged on to social networks making it a challenge to measure the success of these networks.

Lastly those who indicated lack of technology referred to the resources. Usually students and lecturers are not capacitated with the adequate resources by the HLI to be in a position to implement or apply the mobile and social networking platforms. Another problem linked to lack of technology is infrastructure, the respondents believe that there is a need for adequate state of the art and upcoming infrastructure for successful implementation of mobile and social networking technologies in South African HLIs. Some of the equipment include tablets (which were issued out to all students at Univen), iPads and mobile smartphones that allow easy and quick access to Internet.

\section{CONCLUSION AND RECOMMENDATIONS}

The study clearly aimed at identifying and understanding the various mobile and social networking technologies that can be used by University of Venda and University of Limpopo. Thus the research objectives were mainly to identify the various mobile and social networking technologies that can be utilized by the two universities in facilitating increased adaptations. More so, the document addressed the challenges which the two universities have been facing in adopting mobile and social networking technologies for teaching and learning, as well as the benefits and costs they incur in the process. There are many social networks which can be used by students and lecturers in developing their curricula and improve teaching and learning, some of which include Facebook, Twitter, WhatsApp and YouTube and the majority of students and lecturers use them and spend most of their time connected to them.

Challenges which include infrastructure, small screens of devices, poor connection and lack of technology were also revealed in the research findings. It was also revealed in the study that HLIs would incur Internet and infrastructure development costs, that they also stand to benefit in terms of improved teaching and learning, improved communication between students and lecturers and publicity, as well as increased participation.

From the study, it can be concluded that there are three basic areas which are underlying the study of mobile and social networking technologies in HLIs, namely technology, students and lecturers. HLIs which consider mobile and social networking technologies as learning management systems applications need to understand the information technologies upon which they are built, including the Internet and World Wide Web (WWW), and a host of complementary technologies - personal computers, local area networks, client server computing, packet-switched communications, protocols such as Internet Protocol (IP), GML, among others.

While providing the infrastructure, HLIs should also understand the teaching and learning improvements, which are associated with mobile and social networking technologies. This will in turn lead to extraordinary lecturers and students being produced by a particular HLI that creates an interest and excitement in mobile and social networking adaptations in HLIs. Lastly, students and lecturers are criti$\mathrm{cal}$ for the success of mobile and social networking adaptations, primary societal issues, which affects 
students and lecturers includes intellectual property of information which they post on the web, individual privacy and public policy. An understanding and analysis of these three major aspects by HLIs will help them in conceptualizing mobile and social networking technologies. This instils the student/ lecturer-oriented mobile learning strategies in their HLIs.

There is high potential that mobile social networking technology will continue to propagate through all education systems, with greater needs for students and lecturers to be well acquainted to all the technological breakthrough in the system. Research can be explored on the regulation of mobile and social networking technologies in HLIs and the Web by the South African government. Such a survey will bring out best analysis of security issues as the major threat to mobile and social networking adaptations and provide for answers on the best ways to assure secure downloads on the web by lecturers and students.

\section{REFERENCES}

1. Alassiri, A. A., Muda, M. B., Ghazali, R. B., \& Ahamefula U. C. (2014). Usage of social networking sites and technological impact on interaction enabling features. International Journal of Humanities and Social Sciences, 4, 46-61. Retrieved from https:// scholar.google.co.za/citations?us er=03GvZNQAAAAJ\&hl=en \&o $\mathrm{i}=\mathrm{ao}$

2. Banks, K., \& Burge, R. (2004). Mobile Phones: An Appropriate Tool for Conversation and Development? Fauna And Flora International.

3. Chen, C. K., \& Almunawar, M. N. (2016). Cloud Computing in Higher Education. In Impact of Economic Crisis on Education and the Next-Generation Workforce. IGI Global.

4. Lai, K. W., Khaddage, F., \& Knezek, G. (2013). Blending student technology experiences in formal and informal learning. Journal of Computer Assisted Learning, 29, 414-425. Retrieved September 26, 2017 from https:// www.learntechlib.org/p/154029/

5. Larivière, B., Joosten, H., Malthouse, E. C., Van Birgelen, M., Aksoy, P., Kunz, W. H., \& Huang, M.-H. (2013). Value fusion: The blending of consumer and firm value in the distinct context of mobile technologies and social media. Journal of Service Management, 24, 268293. Retrieved from http:// www.emeraldinsight.com/doi/ abs/10.1108/09564231311326996
6. Lu, X., Yu, Z., Guo, B., \& Zhou, X. (2014). Predicting the content dissemination trends by repost behavior modeling in mobile social networks. Journal of Network and Computer Applications, 42, 197-207. https://doi.org/10.1016/j. jnca.2014.01.015

7. Madiba, M., \& Cross, M. (2005). Professional development a case for institutional e-learning training. Proceeding of the World Conference on E-Learning in Corporate, Government, Healthcare, \& Higher Education, Vancouver BC, Canada, Association for the Advancement of Computing in Education (AACE).

8. Magrath, V., \& Mccormick, H. (2013). Marketing design elements of mobile fashion retail apps. Journal of Fashion Marketing and Management: An International Journal, 17, 115134. Retrieved from http:// www.emeraldinsight.com/doi/ abs/10.1108/13612021311305173

9. Mircea, M., \& Andreescu, A. I. (2011). Using cloud computing in higher education: A strategy to improve agility in the current financial crisis. In Communications of the IBIMA. Retrieved from http:// ibimapublishing.com/articles/ CIBIMA/2011/875547/

10. Osang, F. B., Ngole, J., \& Tsuma, C. (2013). Prospects and Challenges of Mobile Learning Implementation in Nigeria. Case Study National Open University of Nigeria NOUN. Proceeding of the International Conference on ICT for Africa (pp. 20-23).
11. Park, S. J., \& Lim, Y. S. (2014). Information networks and social media use in public diplomacy: a comparative analysis of South Korea and Japan. Asian Journal of Communication, 24, 79-98. http:// dx.doi.org/10.1080/01292986.2013 .851724

12. Selwyn, N. (2010). Looking beyond learning: Notes towards the critical study of educational technology. Journal of Computer Assisted Learning, 26, 65-73. https://doi.org/10.1111/j.13652729.2009.00338.x

13. Selwyn, N. (2012). Social media in higher education. The Europa world of learning, 1-10. Retrieved from http://sites.jmu.edu/flippEDout/ files/2013/04/sample-essay-selwyn. pdf

14. Selwyn, N. (2011). Social media in higher education. In The Europa World of Learning (62 ${ }^{\text {nd }}$ edition) (pp. 3-7). Routledge, London.

15. Sharples, M. (Ed.). (2006). Big issues in mobile learning (Report of a workshop by the Kaleidoscope Network of Excellence Mobile Learning Initiative). UK: University of Nottingham. Retrieved from https://telearn.archives-ouvertes.fr/ hal-00190254/document

16. Wankhade, N. V., \& Deshpande, S. P. (2015). A Conceptual framework of distributed mobile database for m-learning. Retrieved from https://www.researchgate.net/publication/280638054_A_Conceptual_framework_of_distributed_mobile_database_for_m-learning 